\title{
The linguistic construction of space in Ewe'
}

\author{
FELIX K. AMEKA
}

Ahstract

This paper presents the linguistic means of describing spatial relations in Ewe with particular emphasis on the grammar and meaning of adpositions. Ewe (Niger-Congo) has two sets of adpositions: prepositions, which have evolved from verbs, and postpositions which have evolved from nouns. The postpositions create places and are treated as intrinsic parts or regions of the reference object in a spatial description. The prepositions provide the general orientation of a Figure (located object). It is demonstrated that spatial relations, such as those encapsulated in "the basic topological prepositions at, in and on" in English (Herskovits 1986: 9), are not encoded in single linguistic elements in Ewe, but are distributed over members of different form classes in a syntagmatic string. The paper explores the role of compositionality and its interaction with pragmatics to yield understandings' of spatial configurations in such a language where spatial meanings cannot be simply read off one form. The study also examines the diversity among languages in terms of the nature and obligatoriness of the coding of relational and ground information in spatial constructions. It is argued that the range and type of distinctions discussed in the paper must be accounted for in semantic typology and in the cross-linguistic investigation of spatial language and conceptualisation.

\section{Introduction}

The primary purpose of this paper is to describe the way in which spatial situations are linguistically constructed in Ewe, ${ }^{2}$ a West African language which belongs to the Kwa branch of the Niger-Congo family. The aim of the paper is to elucidate the Ewe solution to the problem of how to specify the relation of the Figure and the Ground in spatial description (cf. Levinson 1992: 11). The linguistic resources central to the Ewe solution involve adpositional elements - both prepositions, which have evolved from verbs, and postpositions, which have developed from nouns. 
Thus the bulk of the paper describes the grammar and meaning of adpositional constructions. It is assumed that a good grasp of the Ewe means of describing spatial scenes can provide some insightful clues to an understanding of the conceptual packaging of space in Ewe and can help clarify the range and type of distinctions which must be accounted for in semantic typology.

What is theoretically interesting about the Ewe solution to the specification of the relation between Figure and Ground is that spatial relational information is found to be coded in the exponents of at least two formal classes in a syntagmatic string: spatial predicates-prepositions and/or verbs - and postpositions. This coding strategy found in Ewe and other African (and Asian) languages is different from the coding strategy in Indo-European languages where such information is usually expressed by elements from a single form class, the preposition class. While there is no shortage of literature on the Indo-European system, the Ewe system and similar ones are relatively less understood especially in terms of how the different elements interact to produce spatial descriptions (but cf. Sinha et al. 1994).

The second purpose of the paper, therefore is to explore the processes and mechanisms for the interaction of the various elements-spatial predicates, verbs, prepositions, postpositions, locative nouns etc.- used to describe a spatial scene and the interpretation that the composite of their meanings produces when it interacts with pragmatic and world knowledge. In pursuing this goal, a "two semantics model" of meaning is adopted (see Wilkins 1986, 1989 and 1992; and Wilkins and Hill 1995 [this issue] for applications of this model). In this model it is assumed that there are two levels of semantics: semantics1 comprises the stored meanings of signs - lexemes, grammatical constructions, illocutionary devices and gestures - and a set of (non-context bound) principles of composition; semantics 2 is concerned with the on-line contextualised meaning/interpretation. Semantics1 feeds the pragmatics which consists of rules of speaking and conversational implicatures etc. and through their interaction semantics 2 is produced. Using this model, it will be shown that the interpretation of spatial constructions in Ewe involves the following:

(i) the combination of the semantics of prepositions and of postpositions;

(ii) the interaction of the semantics of a preposition and a spatial orientation feature of the verb in a situation; and

(iii) the interaction between the output or default interpretation of the compositional semantics of the elements and general conversational implicatures. 
The discussion will proceed as follows. First, the components of a spatial construction in Ewe are introduced and further clarifications are given for the goals of the study. This is followed by a description of the adpositions. Sections 4 and 5 deal with Ewe postpositions and prepositions respectively. Section 6 investigates the semantics of the spatial predicate $l e$ 'be at' in its uses as a verb and as a preposition. Section 7 then outlines the ways in which the semantics of the individual elements in a spatial construction interact and unify to produce the interpretations of spatial scenes. Finally, in section 8 the Ewe system of spatial description in its various aspects is compared with the systems found in other languages.

\section{Ewe spatial constructions: Some preliminary remarks}

Ewe is a grammatical word-order language with basic SVO syntax (and subject and object are morphologically unmarked). Alternative orders of OSV, OVS and SOV are systematically linked to this basic one, determined by semantic and pragmatic factors. It is also an isolating languge with agglutinative features; as such, word classes in Ewe are largely established on the basis of structural position properties and functions of words.

In an Ewe spatial construction, a Figure - an object (or event) that is located -is coded as an NP (or a clause); a reference object is coded as an NP which is dependent on a postposition that specifies a search domain with respect to the reference object. The reference object NP and the postposition form a constituent-a postpositional phrase which may function as a clausal object, i.e., as an argument of a verb, if the main verb of the clause is a spatial predicate as in (1), or as an object of a preposition, if other verbs are used to characterize the core event as in (2) and (3). This constituent as a whole is the Ground. ${ }^{3}$ Finally, the relation between the Figure and the Ground is expressed by a spatial predicate, a verb and/or a preposition which invariably indicates the static or dynamic nature of the relation. Consider the way in which the categories of a spatial configuation map on to a sentence as illustrated below:

Figure Relation Ground

$\begin{array}{llll} & & \text { reference object } & \text { search domain }{ }^{4} \\ \text { (1) Dadi lá } \quad m l \dot{b} & a b a ́ r & d z \dot{i} \\ \text { [cat DEF][lie] } & \text { [[mat } & \text { [upper surface]] }\end{array}$
'The cat is lying/sleeping on the mat.' 
Figure

(2) Dadi lá

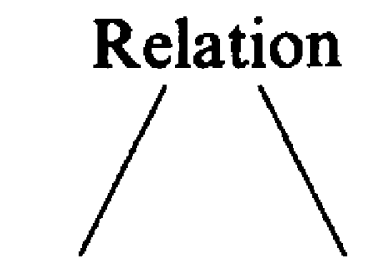

Ground

reference search

object domain

[cat DEF] lie down [ALL] [[mat] [upper surface]]

'The cat lies on the mat.'

(3) É- fle agbalẽ lá le fiásé me

3SG buy book DEF at shop containing regions of 'S/he bought the book in the shop.'

Figure

Relation

reference search

object domain

(3)

a. É- fle agbalẽ lá le

fiásé

me

3SG buy book DEF at

shop

containing

region of

'S/he bought the book in the shop.'

Figure

\section{Relation}

reference search

object domain

b. É- fle agbalẽ lá le

3SG buy book DEF at fiásé

shop me

containing

region of

'S/he bought the book in the shop.'

In sentence (1) the posture verb $m l \dot{b}$ 'lie' is the main verb of the clause and it is the spatial predicate that signals the relation between the Figure dadi la' 'the cat' and the Ground. In sentence (2), however, this relation is expressed by the allative preposition dé 'to(wards)' and partially by the phrasal predicate mls anyi 'lie down'. The sentences in (1) and (2) essentially describe the same spatial scene but (2) emphasizes the change of location of the Figure while (1) focusses on the stative nature of its location. In both sentences the search domain is specified by the postposition $d z i$ ' 'upper surface', that is, the part of the reference object where the Figure is located. In both sentences the meaning of the spatial predicate plus that of the postposition combine to produce a locative description of the Figure.

Sentence (3) can be interpreted in one of two ways as represented in (3a) and (3b) respectively: The clause denoting the event Éfle agbale 'S/he bought a book' can be construed as the Figure and fiásé 'shop' as the reference object while the postposition me 'containing region of' specifies the search domain with respect to the reference object where the Figure, i.e., the event, is located. Together the reference object and the 
postposition constitute the Ground. The preposition le 'at' indicates the relation between the Figure and the Ground. Alternatively one can think of Efle 'S/he bought' as an external situation to the locative description and consider agbalẽ lá 'the book' to be the Figure. In this case the other elements have the same functions as outlined with respect to the first reading. These two readings can be distinguished on the basis of the focussing facts. Thus fiásé 'shop' can be fronted for focus in answer to the question 'Where did s/he buy the book?' Similarly, agbale 'book' can be focussed as if in answer to the question 'What did s/he buy in the shop?'

When one looks at the free English translations of the Ewe sentences in (2) and (3) for instance, and tries to determine what the correspondences are between the items, one is struck by the fact that the English prepositional meanings are expressed by an Ewe preposition and a postposition. Thus on is rendered by dé 'to(wards)' and $d z i$ 'upper surface' in (2) while in is rendered by le 'at' and me 'containing region of' in (3). This is a point that is made in several pedagogical grammars of Ewe. A recent one comments as follows: "Les prépositions locatives (dans, sur, a) correspondent en éwé à la fois à un verbe et à un nom locatifs: sur la route: le mó $d z i$ sur: le ... dzi",5 (Rongier and Tsevi 1988: 24).

Thus, in a sense, the fact that the spatial relational information is not coded in one form but is expressed in two words in the sentence is recognized, albeit intuitively, by practical grammarians.

On another level, when one looks at sentence (1) above, one could be led to think that $d z i$ 'upper surface' by itself stands for on. Indeed Westermann suggests this when he notes that in a sentence like the following:

$$
\text { é- le to } d z i
$$

3SG be-at: PRES river upper surface

'He is on the surface of the water.'

"dzi stands both for 'surface' and for 'on'" (Westermann 1930: 54). Westermann's views are based on translation rather than semantic analysis. I want to argue in this paper that the concept of on and other prepositional meanings are derived in Ewe by the compositional semantics of prepositions and postpositions. If this view turns out to be correct, then the Ewe data pose a challenge to some of the claims of the universality and the basic nature of some prepositions that have been made in the literature. For instance, Herskovits (1986: 127) asserts that:

$A t, o n$ and in constitute in English a fundamental set of prepositions, with a large number of distinct types of uses derived from three ideal meanings which are cognitively basic, essentially topological relations ... the ideal meanings of 
at and in, respectively coincidence and surrounding are topological relations preserved under elastic deformations, but the ideal meaning of on involves the physical relation of support in addition to the topological relation of contiguity in the three dimensional case.

In a more restricted reading, perhaps all Herskovits is saying is that these are "cognitively basic" for English. But the passage at least suggests the possibility of a more universal claim. In any case, the Ewe data point to the view that what may be universally cognitively basic with respect to on, for example, is the atomic components that Herskovits postulates and it is not the molecular structure 'on' that is basic and universal.

The following is an excerpt from a text in which a teacher and her pupils are talking about houseflies. This text illustrates again that the characteristic and common way of expressing spatial relational meanings in Ewe is by a combination of spatial predicates and postpositions. These elements are not italicized. The reader is invited to compare the glosses of the Ewe terms with the free English translations.
a. $N$
Tag housefly be insect common INDEF 'The housefly is a common insect.'

b. $\quad \dot{E}-$ le $d u$ sia $d u$ me.

3SG be-at: PRES town every town containing region of 'It is in every town.'

c.

$$
\dot{E}-\quad \text { no- } \quad a \quad \ldots x o
$$

3SG be-at: NPRES HAB building me. containing region of 'It stays ... in rooms.'

d. D: $\quad$ E- vá dze dé gli yú le Atsú gbó. 3SG come land ALL wall side at Atsú vicinity 'It came and perched on the wall near Atsú.'

e. F: Me-kpó-e le mángo-tí té kpó. 1SG see 3SG at mango-tree under PFV 'I once saw it under a mango tree.'

(Nunyamo 2B: 39-40, see Ewe Texts in references)

\section{The development of adpositions}

In Ewe, as in many languages of Africa (e.g., Akan [Boadi 1992]; Hausa [Heine et al. 1991b]), Asia (e.g., Thai [Kölver 1984]) and Oceania (e.g., 
To'aba'ita [Lichtenberk 1991a]; Longgu [Hill 1992]), there are two types of adpositional elements. One type is based on and evolved from verbs, and the other type from nouns. Depending on the typology of the language, both groups may function as prepositions or as postpositions. In some Oceanic languages, for example To'aba'ita, there are verb-like prepositions and noun-like prepositions (see Lichtenberk 1991a: 40-48). In some African languages also, the two classes of adpositions are prepositions. Thus Hausa and Maa, for example, have both verb-like and nounlike prepositions. In other African languages, especially the Kwa languages (e.g., Akan, Ewe and Ga), however, the verbal adpositional elements tend to be prepositions and the nominal adpositional elements tend to be postpositions. These adpositional elements have been explicitly or implicitly compared with the prepositions of Indo-European languages in the reference grammars and in theoretical discussions of some of these languages.

Thus with respect to the Ewe terms, Westermann (1930: 51) comments on the evolution and function of nominal adpositions as follows: "Substantives of place are substantives which are employed to indicate place .... These substantives of place often do the work of English prepositions, adverbs, and conjunctions." He adds that "[T] hese substantives of place may be called postpositions because they always follow a substantive or pronoun" (1930: 52) ${ }^{6}$ Regarding the verbal adpositional elements, he observes that "many verbs when they stand next to others play the part of English prepositions, adverbs or conjunctions" (p. 129). Following the same system that Westermann used in naming the nominal adpositions, we may call the verbal adpositions prepositions because they occur before their dependent nominal constituents. This phenomenon and Westermann's observations raise a number of questions that have preoccupied students of Ewe and similar languages to varying degrees. One of these issues relates to grammaticalization. Investigators interested in this topic have mainly researched the following questions: (i) what processes underlie the grammaticalization or development of lexical verbs and nouns to adpositions; (ii) what are the semantic sources from which the terms develop and what semantic types develop into what specific meanings (see e.g., Heine 1989, Heine et al. 1991a, b on Ewe and other African languages and Bowden 1992, Lichtenberk 1991b on Oceanic languages). These questions of grammaticalization are only tangentially addressed in this paper.

Two other interrelated analytic issues are triggered by the phenomenon of the co-existence of two types of adpositions in a language. These issues are based on the observation that the two types of adpositions have functions that parallel those of prepositions in Indo-European languages. 
In fact, Heine et al. (1991b) have contrasted the Ewe system and the Indo-European system perceptively as follows: "Viewed from the perspective of Ewe, ... prepositions in European languages may be called portmanteau markers since they combine the function of both $\mathrm{V}$ - and $\mathrm{N}$-adpositions" (Heine et al. 1991b: 144). If this is the case then one of the things that one would like to know is what functions are performed by the verbal adpositions and which functions are performed by the nominal adpositions. A second issue worth investigating is what the semantic and typological consequences are when a verbal adposition combines with a nominal adposition in these languages to express a concept that is coded by a single preposition in other languages. In other words, if prepositions in Indo-European languages constitute the form class of spatial relational elements, but their functions are distributed aross two or more form classes in other languages like Ewe, then one would like to know if this correlates with other factors. These issues have received less attention in the literature although there are some insightful hints available. (See section 7 for further elaboration.)

\section{Ewe postpositions}

In this section, I present an overview of the postpositions in Ewe describing their semantic and syntactic properties. This will pave the way for a discussion of their interaction with prepositions in spatial description in subsequent sections.

Postpositions, which are nominal in origin, constitute a closed class of grammatical items in Ewe. They may have spatial, temporal, causal and other uses. In this paper, I am only concerned with their spatial uses. The postpositions, as Westermann observed, are terms that denote places. They designate and create places as entities (as opposed to place as a relation, see the discussion of the prepositions below), as is evident from the use of some of them in the following examples.

(6) Kplĩ gã́ dzí fo di.

table big upper surface beat dirt

'The top of the big table is dirty."7

(7) Kplo ati- á dome. sweep tree DEF under 'Sweep under the tree.'

In Ewe grammar, postpositions are typically construed either as parts or part defined regions inherently related to objects, this is evident from the way in which they are coded in the grammar with respect to the nominal 
reference objects, i.e., in possessive constructions. There are two possessive constructions in Ewe: one that makes use of a possessive connective $f e ́$ to link the possessor and the possessum, and another in which the possessor and the possessum are juxtaposed to each other without any intervening connective. The possessive connective construction which is used for general possession and ownership and also for relations between a body and its parts presents the relation between the entities as less inherent. The construction involving the juxtaposition of the entities is used to express kin and social relations and presents the relationship as an inherent one. This juxtaposition construction is also used to indicate the relation between the intrinsic parts of an object and the object as in examples (5d) and (6) above. Thus the relation is presented as an inherent one. In this way, body parts and other part terms (some of which are the historical sources for some of the postpositions) are treated differently from the postpositions (see Ameka 1991, in press; Claudi and Heine 1986; and Heine 1989 for the details).

A further piece of evidence for the view that the spatial regions and parts of an object are generally treated as more inherent to the object than body parts or component parts are comes from the fact that body parts can participate in a "possessor raising" construction while the postpositions cannot. Compare the following pairs of examples:

(8) a. Áma tútú Kofí fé ykúme.

Ama wipe Kofi poss face

'Ama wiped Kofi's face.'

b. Áma tútú gkúme ná Kofí.

Ama wipe face to Kofi

'Ama wiped the face for Kofi.'

a. Áma tútú kplõ-á dzí.

Ama wipe table DEF upper surface

'Ama wiped the table top.'

b. * Áma tútú dzí ná kpls̃-á.

Ama wipe upper surface to table DEF

lit: 'Ama wiped the top for the table.'

Table 1 gives a list of the core members of the class of postpositions in Ewe (cf. Westermann 1930: 52-54; Duthie in press).

A perusal of the terms and their glosses shows that some designate intrinsic parts or "axially determined parts", to use the words of Landau and Jackendoff (1993), such as nü 'entrance, end point'; pú/pútí 'outer surface'; and $m e$ 'containing region of'. Others denote spatial regions 
Table 1. Ewe postpositions and their sources

\begin{tabular}{|c|c|c|c|}
\hline Postposition & Gloss & Putative sources & Source gloss \\
\hline dome & 'between, among' & & \\
\hline$d z i$ & 'upper surface' & & \\
\hline dome & $\begin{array}{l}\text { 'bottom, } \\
\text { under part/region, underneath, } \\
\text { under' }\end{array}$ & $\begin{array}{l}<d o \\
\quad(m e)\end{array}$ & 'vagina' \\
\hline$f o(m e)$ & '(flat, horizontal) surface ?? midst' & $\begin{array}{l}<f o \\
\quad(m e)\end{array}$ & 'belly' \\
\hline gbó & 'vicinity' & & \\
\hline gódo & 'outside' & & \\
\hline gódzí & 'in the direction of' & & \\
\hline gome & $\begin{array}{l}\text { 'bottom, } \\
\text { under part/region, underneath, } \\
\text { under' }\end{array}$ & $\begin{array}{l}<\text { ago } \\
\text { <agome }\end{array}$ & $\begin{array}{l}\text { 'anus, } \\
\text { buttocks' }\end{array}$ \\
\hline kasa & 'adjacent to' & & \\
\hline lofo & 'around' & & \\
\hline me & 'containing region of' & & \\
\hline megbé & $\begin{array}{l}\text { 'back part, the place behind an } \\
\text { object, behind, after' }\end{array}$ & $\begin{array}{l}<m \check{e} \\
-g b \dot{e}\end{array}$ & $\begin{array}{l}\text { 'back } \\
\text { region' }\end{array}$ \\
\hline$\eta g \jmath(g b e ́)$ & $\begin{array}{l}\text { 'front, the place in front of an } \\
\text { object, forwards, before' }\end{array}$ & $<? \eta g g o ́$ & 'forehead' \\
\hline$n \check{u}$ & 'entrance, end point' & $<n \check{u}$ & 'mouth' \\
\hline pú/pútí & 'outer surface' & $<\eta \dot{u}\left(t i^{\prime}\right)$ & 'skin (of body)' \\
\hline ta/tame & $\begin{array}{l}\text { 'point, peak, upper end, over, } \\
\text { ?above' }\end{array}$ & $\begin{array}{l}<t a \\
m e\end{array}$ & 'head' \\
\hline té & $\begin{array}{l}\text { 'bottom, } \\
\text { under part/region, underneath, } \\
\text { under' }\end{array}$ & & \\
\hline tó & 'edge' & $<t o ́$ & 'ear' \\
\hline titína & 'middle' & & \\
\hline$x \check{a}$ & 'beside' & $<a x a ̆$ & 'side (of body)' \\
\hline
\end{tabular}

anchored to reference objects such as gbó 'vicinity'; gódzi 'in the direction of'; gódo 'outside'; xă 'beside'. There are others which can be used to designate parts or regions such as megbe 'back part, the place behind an object'; té/gome/dome 'bottom, under part or region, underneath, under'.

This distinction between postpositions that denote parts and those that denote regions and those that can represent both has not been made explicit in descriptions of these terms, although it has consequences for the grammatical behavior of the postpositions. Thus one can only stack postpositions which designate regions as in (10):

(10) Tsó agbalè- $a$ da dé Kofí gbó lofo.

take book DEF put ALL Kofi side around

'Put the book somewhere near Kofi.' 
A second consequence of the distinction is that some region descriptions can be derived by grammatical means. Thus the region anchored to a specific part may be coded by linking the term for the intrinsic part to the object by the possessive connective. Compare the difference between the following pair of sentences:
a. Xeví-lá le oxo- á
bird DEF be-at: PRES house DEF
ta-me.
head-containing region of
[the bird is at the apex of the house]
'The bird is on top of the roof.'

b. Xeví-lá le xo- á fé

bird DEF be-at: PRES house DEF poss

ta-me.

head-containing region of

[the bird is at the area of the apex of the house]

'The bird is above the roof.'

The generalization is that when postpositions which indicate spatial parts occur in the NP fé $\mathbf{N}$ construction, they are interpreted as designating regions that are anchored to those parts of the object. This generalization sheds light on the interpretation of NP fé $\mathrm{N}$ constructions where the $\mathrm{N}$ is a multifunctional item which is ambiguous between a body part and a spatial term. For instance, Heine et al. (1991 b: 66) provide the following sentence as an example in a stage of the development of the body part lexical item megbé 'back' to a postpositional grammatical item precisely because of its ambiguous nature:

(12) dzra xo- a fé megbé dó prepare house- DEF poss back VS

a. 'Prepare the back wall of the house.'

b. 'Prepare the place behind the house.' (interlinear gloss modified F.A.)

The ambiguity of this sentence arises, in my view, from two sources. The first is the use of the NP fé $\mathbf{N}$ [spatial part term] structures to express regions. Thus since megbe is a spatial term this construction triggers the region interpretation as we have been discussing. The second interpretation arises from the possibility of the figurative mapping of body parts onto the parts of objects by analogy in Ewe. In this case the body part terms as in (12) above occur with the possessive connective. Hence in the interpretation of the sentence involving the back wall one can say 
that 'back' is an imposition of an anthropomorphic perspective on the house.

This distinction also illuminates the behavior of expressions that are derivatives of body parts and postpositions. There are two kinds of such derivatives: (i) The derivatives that denote body parts or regions on the body, for instance, $n k \dot{u}$ 'eye' vs. $\eta k \dot{u}$-me 'eye-in, i.e., face'; $a b s$ 'arm' vs. $a b$ - $t a$ 'arm-upper end', i.e., 'shoulder'. These are more or less lexical compounds. The function of postpositions in these compounds is consistent with their use (outside the spatial domain) as derivational formatives. (ii) The derivatives that do not denote body parts but rather spatial regions adjacent to the parts, for instance $a x a-d z i$ 'side-upper surface, i.e., region beside something'; $a f$ - $n$ ŭ 'foot-entrance, i.e., the foot region of something'. Both types of derivatives are linked to their possessors by the possessive connective. However, I think that there are different motivations that underlie the use of the possessive connective by the two groups.

The explanation for the first group is straightforward. They take the possessive connective because they are body-part terms. This behavior is consistent with the behavior of other body-part terms in the language. The behavior of the second group in taking the possessive connective seems at first to be inconsistent with the distribution of the possessive marker in the language. The members of this group are spatial orientations and spatial orientation terms are typically juxtaposed to their reference objects. What is even more intriguing is that the members of this group never occur juxtaposed, unlike tame 'apex', for example, which has both possibilities. This enigma has a simple explanation: the occurrence of these terms with the possessive connective is used to signal that they are used to designate regions adjacent to their reference objects. Compare the following sentences which are nearly but not fully synonymous.

a. $\quad \dot{E}-\quad$ no Kofí $x a$.

3SG sit Kofi beside

'He is sitting beside/next to Kofi.'

[He would be the person sitting closest to Kofi on one side.]

b. 'E- no Kofífé áxa dzí.

3SG sit Kofi poss side surface

'He is sitting on Kofi's side/beside/next to Kofí.'

[There may be other people sitting between him and Kofi, but he would be sitting in the region adjacent to Kofi's side.]

The word $x a$ is a postposition which evolved from the body part term 
axa 'side' and axa-dzi is made up of axa 'side' and the postposition $d z i$ 'upper surface'. These two expressions can be used to denote the same real world situation, i.e., something being located in the area adjacent to something else. However, they code different perspectives on this real world situation, as I tried to indicate in the examples above. It seems to me that one can only appreciate the linguistic difference between the two sentences if one recognizes the two main points that have been made concerning postpositions and the possessive connective in this section. These are: (i) that there is a distinction between those postpositions which denote regions and those that designate intrinsic or axial parts; and (ii) postpositions that are derivatives of body parts and postpositions which denote or are used to describe regions may be linked to their reference objects by the possessive connective rather than being juxtaposed to them.

To sum up, in the terminology used in this study and in terms of spatial description, one can say that the postpositions are used to encode the search domain with respect to the reference object where the Figure is located. I have indicated that apart from the use of the postposition in their unmarked NP N constructions, they can also occur in the NP fé $\mathrm{N}$ constructions where they indicate regions anchored to parts of objects. Similarly, constructions in which postpositions function as derivatives attached to body or object part terms are interpreted as representing a region anchored to the part of the person or object denoted by the part term. In all these cases what postpositions do, it seems to me, is to create places as entities. But these places are part defined and (inherent in the localized situation) to other objects. All the different constructions in which postpositions are involved can be thought of as mechanisms of identifying the particularized search domain in a spatial configuration. Having described the postpositions we now turn to the prepositions.

\section{Ewe prepositions}

The postpositions by themselves do not give sufficient information for locating entities in space. They only provide information about relevant aspects of the search domain with respect to the reference object. We need to relate the Figure to the reference object. This is the role of spatial predicates - prepositions and spatial orientation verbs.

Prepositions in Ewe constitute a small closed class of less than ten elements. The established members of the class are given in Table 2 with an indication of their verbal sources. Since the prepositions have evolved from verbs they have been referred to as a class of verbids (Ansre 1966). However, the term does not correspond uniquely to the preposition word 
Table 2. Ewe prepositions

\begin{tabular}{llll}
\hline Preposition & Gloss & Verbal sources & Source gloss \\
\hline$l e$ & 'at' & $<l e$ & 'be at' \\
$d \dot{e}$ & 'to, towards' & $<d e ́$ & 'enter' \\
$t s o ́$ & 'from' & $<t s o ́$ & 'originate, arise' \\
$t o ́$ & 'through' & $<t o ́$ & 'pass' \\
$n a ́$ & 'to, for' & $<n a ́$ & 'give' \\
$k p l e ́$ & 'with' & $<? k p e ́+$ & 'meet' \\
& & $d \dot{e}$ & 'enter' \\
vásédé & & $<v a ́$ & $=$ 'accompany' \\
& 'until' & $s e ́$ & 'come' \\
& & $d \dot{e}$ & 'stop' \\
\hline
\end{tabular}

class. This is because it is also used to characterize other words which have evolved from verbs but which belong to different word classes such as modals, perfective aspect markers and verbal satellites. Serial verb constructions (SVCs) have been identified as the channel for the general development of verbs into verbids (see Lord 1993, and references therein for some views on the mechanisms of this syntactic change). The fact that the class of prepositions in Ewe is the result of the grammaticalization of verbs has consequences for the properties of the elements in the class.

Synchronically, and as is evident from a comparison of the verbal and prepositional forms above, all the prepositions except one, kplé 'with', are identical in form and are semantically related to their verbal counterparts. The preposition kple 'with' is identical in form and is related, through grammaticalization, to the NP co-ordinator kple 'and'. At this stage, it is appropriate to introduce a terminological distinction. Polysemy is used in this paper in a narrow sense to refer to a relation between different senses of a lexeme. That is to say that polysemy is a relation between the different senses of a word whose forms belong to the same word class. If the forms and the different but related senses belong to different classes then we are dealing with different but related lexemes and hence the relationship between them is taken to be one of heterosemy (cf. Lehrer 1990 who uses polysemy for both kinds of relations distinguished here). The relationship between the verbal and prepositional forms can be described as a case of heterosemy rather than polysemy for at least two reasons: Firstly, because the forms belong to different morpho-syntactic categories; and secondly, because there is a diachronic relationship between the forms and their respective senses (cf. Lichtenberk's [1991b] definition of heterosemy). 
One cannot really talk of such a relationship existing between the preposition vásédé and its verbal counterparts. Nevertheless, its origin is quite transparent. It is the result of the compounding of the three verbs: $v a$ 'come'-sé 'stop'- dé 'enter'. The combined semantics of these verbs is consistent with the meaning of the preposition. The source of kple is not that transparent. It has been suggested that it comes from a fusion between kpé 'meet' and dé 'enter' (Westermann 1905, cf. Heine and Reh 1984). That is to say $k p \dot{e}+d \dot{e} \rightarrow k p \emptyset d \dot{e} \rightarrow k p l e ́$. This makes sense phonologically. The process would have involved the deletion of the last vowel of $k p \dot{e}$ which would have yielded the form ${ }^{*} k p q \dot{e} .^{8}$ This development makes semantic sense as well. The bridging context for such a development would have been the verbal expression $k p e ́$ dé $X$ pú. In this construction, the verb $k p \dot{e}$ 'meet' obligatorily takes a prepositional phrase complement introduced by the allative preposition $q \dot{e}$ 'to' with its object as a postpositional phrase headed by $\eta^{\prime}$ 'outer surface'. The expression may be contextually interpreted as 'to help $\mathrm{X}$, to accompany or add to $\mathrm{X}$ '. These contextual meanings are plausible sources for the development of a comitative/instrumental preposition (cf. Stolz and Kilian-Hatz 1992).

Even though these prepositions have developed from verbs, they can still be distinguished from verbs on morpho-syntactic grounds. Prepositions can be distinguished from verbs on the basis of their function and distribution, i.e., the structural slot in which they occur. Prepositions (and verbids in general) cannot function as the main predicate of a clause. Verbs, on the other hand, have this function. Thus in an unmarked monoverbal clause a preposition occurs in the following frame: NP V (NP)-NP. Words which occur in this slot and contribute to the identification of the semantic role of the following NP in the clause are prepositions. This last feature is the distinction between prepositions and other verbids such as perfective aspect markers and verbal satellites which may occur in a similar structural slot but do not help in the identification of the roles of NPs. Typically such verbids are not followed by NPs. By contrast, there are no intransitive prepositions in Ewe, they would always have a dependent nominal phrase argument.

Morphologically speaking, the prepositions are not, in general, inflected for the verbal categories of tense, mood or aspect. I say 'in general' because, as we shall see below, some prepositions tend to take some of these categories. This behavior has been explained in the grammaticalization literature as a consequence of the gradualness of grammaticalization where those elements which are optionally inflected for these categories are said to be at an intermediate stage on the cline form verb to preposition (see, for example, Heine and Reh 1984 Heine et al. 1991b; and Lord 1993). From this perspective, kplé 'with', which never takes any inflection, 
has been completely grammaticalized and is at the prepositional end of the continuum. The other prepositions are a step removed from this point. As Westermann (1930: 129-130) observes when discussing the development of verbid elements in Ewe, "[A] certain freedom obtains in the way these words may be used; the same verbs may be considered in the same combination and with the same meaning sometimes as verbs, when they are conjugated, sometimes as invariable prepositions etc., according to the wishes of the speaker." The marking of forms which would otherwise be thought of as prepositions with verbal markers is not as unconstrained as Westermann suggests. It is true that some forms such as ná, tsó, and tó may take the future or habitual when they occur as the second predicate in a clause. When they occur with the future after the main predicate which is also marked for the future or the ingressive, it could be argued that they are functioning as verbs in a serial verb construction or a verb paratactic construction (c.f. Collins 1993 on the use of future marking as a diagnostic for SVCs and verbal parataxis in Ewe).

$$
\begin{aligned}
& \text {.. ye- wó-le vo-vo gé á- tsó } \\
& \text { LOG-PL-be-at: PRESRED-free INGR FUT arise } \\
& \text { é-sí-me } \\
& \text { 3SG-hand-containing region of } \\
& \text { '... they are going to be free from his hands' }
\end{aligned}
$$

(Nyaseto, Nov. 1993, p. 6)

However, some of the prepositional elements can optionally take habitual aspect marking. This occurs under two conditions. First, when the prepositions is stranded (with its object fronted for discourse reasons) and the main predicate is marked for the habitual then the preposition may be optionally marked for the habitual as well. This is the case with le 'at' which is said to have "lost virtually all verbal properties" (Claudi and Heine 1986: 24) in the following fossilized expression:

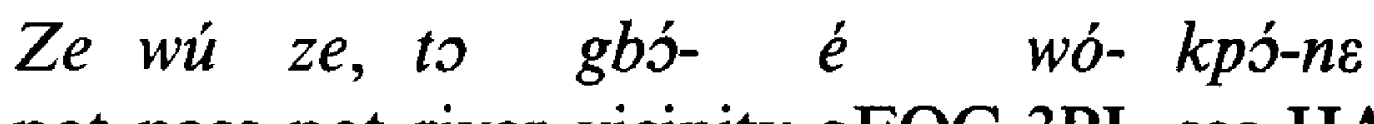
le-na.
pot pass pot river vicinity aFOC 3PL see-HAB: 3SGat-HAB
lit: 'A pot which is stronger than another pot is discovered at the riverside.'

Drawing on the insights of the Cognitive Linguistic analysis of similar phenomena in Gengbe, a sister dialect group of Ewe in the Gbe dialect cluster, presented by Lewis (1989), one can describe the second condition as follows: habitual marking occurs optionally on prepositions when they introduce locative or dative constituents which are attained points or 
places and not intended goals and they follow a main predicate which is also marked for the habitual. Thus dé, the allative preposition, and vásédé 'until' never get a habitual marking, whereas tó, tsó, and ná can optionally take the habitual when they follow a main predicate marked for the habitual, as illustrated below:
Tsi tsa-na tó-(ná) afii.
water flow-HAB pass-HAB here
'Water flows through here.'

(17) $\dot{E}-\quad w o-a$ do ná-(á) ame-wó.

3SG do-HAB work give-HAB person-PL

'S/he works for people.'

(18) E- $\quad x o-a \quad g a$ tsó- (á) noví-á-wó gbó.

3SG get-HAB money originate-HAB sibling-DEF-PL vicinity

'S/he receives money from his/her siblings.'

Another property of prepositions is that they introduce noun phrases and postposition phrases into clauses, forming constituents with them. As such, given the right semantics and pragmatics such prepositional phrases can occur preposed to clauses and marked as background by the appropriate discourse particle. Verbs with their internal arguments cannot be preposed in this way. Since the felicity of preposing a prepositional phrase to a clause is governed by semantic, pragmatic and discourse factors, this property is not shared by all members of the preposition class. For instance, the most fully grammaticalized preposition, kple with its complement never occurs sentence initially. However, le, tó, and tsó are very frequently found sentence initially in texts, as in the example below.

Le mó- á dzí lá, é- kpé ame geqe- wó. at road DEF upper surface TP 3SG meet person several PL 'On the way, he met several people.'

One of the features of five of the seven prepositions listed above-le, dé, tsó, tó, vásédé-which is noted in the literature, is that the complements which they take should be modified by a postposition since the prepositions are locative in nature. The authors are quick to add by way of accounting for the apparent exceptions to the generalization that "[I] $t$ is only when the complement itself is a local noun, for example, a toponym, a name of a place or town that the postposition is ommissible." (Hünnemeyer 1990: 92).

In the rest of this paper I want to show a number of things concerning 
the behavior of postpositions and toponyms. First, I want to argue that the presence of a postposition in locative constructions is not just fulfilling a constraint on the kind of complement that the locative prepositions should take. Rather the postpositions specify the domain with respect to the nominal complement of the preposition within which the Figure is located. Secondly, I want to demonstrate that the conditions on the ommissibility or otherwise of postpositions with respect to toponyms can be best explained in terms of the semantic types of the postpositions. Specifically, postpositions that denote regions occur freely with toponyms, whereas those that denote axial or intrinsic parts never occur with toponyms unless they are used to make a semantic distinction between two or more senses of such a noun. The third point to assert then is that the presence or absence of postpositions with a toponym has semantic consequences and it is not just a meaningless option which may be subject to the whims of the speaker. These issues are addressed in the following sections through an examination of the semantics of le as verb and as preposition. After this, the way in which this semantics interacts with the semantics of the other elements in a spatial construction and the pragmatics of the spatial scenes for the production and interpretation of spatial descriptions is explored.

\section{The semantics of $l e$}

Ansre (1966: 30) suggests that:

three instances of le [should] be recognized in the grammar and lexicon of Ewe:

le 1 the transitive verb 'to be located'

le2 [a form involved in the marking of present progressive]

le3 the verbid [i.e. preposition F.A.]

Many researchers (e.g., Clements 1972; Duthie in press; Heine 1992) agree with this suggestion, even though they may not endorse the labels used to describe the different instances of the form. For example, Heine (1992: 354-355) does not consider le1 as a transitive verb but as an auxiliary which has been grammaticalized in two directions-one as a preposition and the other as a present progressive and present ingressive marker. The proposed three instances of $l e 1, l e 2$ and $l e 3$ are illustrated respectively in $(20 \mathrm{a}, \mathrm{b}$ and $\mathrm{c})$ below.
a. $A w u$
lá le
$k a-a \quad d z i$. garment DEF be-at: PRES rope DEF upper surface 'The garment is on the line.' 
b. Nyónu lá le dó wo-m் gé. woman DEF be-at: PRES work do PROG/ INGR 'The woman is working/is going to work.'

c. É- vá dzo gbe deká béná do gã ádé 3SG come happen day one that famine big INDEF tó le xéxé blibo lá me. start at world whole DEF containing region of 'It came to pass one time that there was a great famine in the whole world.'

In my view, there are only two, not three, instances of le that should be recognized in Ewe grammar and lexicon:

$l e 1$ a verb which subsumes Ansre's le 1 and $l e 2$; and

le2 a preposition which is the same as Ansre's le 3

The arguments in favor of this position will become clear in the course of the exposition. In the rest of this section I disuss the semantics and the properties of the verbal le and the preposition le, I argue that they have very similar meanings and the basic distinction between them lies in the different syntactic functions that they have.

\subsection{The verb le}

There are three main uses of the verb le. These are the existential, the locative and the aspectual uses. These usages are distinguished on the basis of the kind of constituent that functions as the complement of the verb. Thus, for the aspectual use the verb le takes an aspectual phrase headed by the ingressive or progressive aspect marker as in (20b) above. For the locative use, the complement is either an inherently locative nominal phrase as in sentence (21) below, taken from a folk tale about how it came to be that the Spider now lives in cobwebs, or a postpositional phrase as in (20a) above. Note that in the following example the verb's locative complement afima 'there' is fronted for focus.

(21) Afí-ma wò- le vásédé pu ke... place-that 3SG be until day break

'There he was until day break ...'

When the verb le is used to express general existence, it takes an ambient invariable objective pronominal clitic which is underlyingly an $-i$. Two alternative processes of assimilation between the pronominal element and the verb $l e$ are possible in the language. Either the $-i$ assimilates the $e$ of $l e$ to its height to produce $l i$ or the $e$ of $l e$ assimilates the $-i$ to itself 
causing a lengthening of the vowel to become lee. The products of these assimilation processes turn out to be dialect variants, although both forms are available in the standard colloquial dialect. This is consistent with the general morphophonemic changes involving / $i$ / morphs in the language. The orthography does not refect the length difference between the verb le and the verb plus the pronominal complement lee. I have used the lee form in one of the examples below to reflect the actual spoken form:

\section{a. Máwú li}

God be-at: PRES: PRO

'God exists.'/'There is a God.'

b. Tógbé- wó lee

ancestor PL be-at: PRES: PRO

'Ancestors exist.'/'Ancestors are there.'

The general existential form $l i$ or $l e(e)$ may be further complemented by an adverb, typically derived from or related to a property concept, to express the existential condition, state or quality of its subject. In the descriptions of Ewe, adverbs are said to modify the bare verb le. This is misleading because it does not pay attention to the differences between the bare le as used in locative constructions and the fact that the vowel is lengthened when it takes an adverbial complement. It is significant, I think, that in texts one encounters both $l i$ and $l e$ forms followed by an adverb. Compare the following sentences taken from the same author (see Ewe Texts in the references).

(23) Séyrám biá- $e$ bé núka-é ná bé wòSeyram ask 3SG COMP what aFOC cause COMP 3SG li kpóó nenémá máhã?

be-at: PRES: PRO quietly such EMPHQ

'Seyram asked her what at all makes her to be so quiet?' (Akotey 1988: 11)

(24) Wó nya sia le pe $\quad k o$ abé ...

2SG:poss case this be-at: PRES: PRO exactly just like 'This case of yours is exactly just like ...' (Akotey 1988: 14)

In all these uses the verb le has a core meaning which can be paraphrased as follows: 
at this time

$\mathrm{X}$ be at $\mathrm{Y}$

$$
\left\{\begin{array}{l}
Y \text { be an activity/event } \\
Y \text { be a place }
\end{array}\right\}
$$

To account for the different uses, $Y$ has to be specified to reflect the particular contextualization. Thus for the aspectual use, the further specification is that "Y is an activity/event." For the locative and existential uses the specification is that "Y is a place." The first component accounts for the fact that the verb is used only to talk about situations in the present. I will have nothing more to say about the aspectual uses.

What is needed is a justification for the semantic formula for the locative and existential uses, especially concerning the "Y is a place" specification. This aspect of the meaning with respect to the locative use is self evident given the requirement, as it were, that the complement of the verb in this use has to be inherently locative or the locative feature has to be supplied by a postposition. It is not so obvious for the existential use. I would argue however that the invariable pronominal, which is identical in form with the third person singular object pronoun, is the expression of this place element in the existential as well. Thus the presence of the invariable pronoun in the existential structure can be explained by saying that the existence of something implies existence in a place and it is this place of existence which is implicated by the pronoun. This view can be supported with language internal evidence. The co-occurrence of the invariable pronoun and the verb $l e$ in the expression of current or universal existence parallels the use of a generic nominal anyi 'earth, ground, down' in combination with the non-present form of the locative/existential verb, no, to express non-present existence. Compare example (25) expressing non-present existence with example (26) which describes non-present location:
pútsu ádé no
anyi gbadégbe

man INDEF be-at: NPRES ground one day

'A certain man was one day'/'Once there was a certain man' lit: 'A certain man existed one day' (Akpatsi 1980: 1)
$A w u \quad l a ́ \quad n o$
ka- a dzí.

garment DEF be-at: NPRES rope DEF upper surface

'The garment was on the line.' (cf. (20a) above, its present counterpart)

In addition, locative complements, be they inherently locative nominals or postpositional phrases, are mutually exclusive with the invariable pronominal $-i$ or the generic nominal anyí. This suggests a certain degree 
of semantic incompatibility due to a shared semantic feature. This shared semantic feature, I suggest, is the feature of [place]. It is instructive to note that we never get the sequence $l i$ PostpP nor $l i$ NPloc, but we do get li Adv.

Furthermore, the idea of existence being linked to location in a place has been pointed out by several investigators. For example, Bolinger (1977: 99) notes that "To exist, a thing has to be somewhere." 9 This view of existence as location in space has been used to explain and argue for the widespread crosslinguistic expression of existence in locative terms (cf. Clark 1978; Lyons 1977). Indeed, the use of the same verb in Ewe to express location and existence is itself a case in point. Thus the pronoun is present with the verb $l e$ in the existential constructions to designate, as it were, the abstract space of existence.

From these pieces of evidence it can be concluded that "Y is a place," i.e. $\mathrm{Y}$ as a place in relation to something else, is part of the semantics of the verb le when it is used to express existence and location. The same component is present in the semantics of the preposition as we shall see in the following section.

\subsection{The preposition le}

The preposition le has been described as the most important preposition in Ewe and serves as a multi-purpose preposition that is used to introduce NPs with different semantic roles into the clause (cf. Heine et al. 1991b: 142). Indeed this preposition is involved in the expression of locative, temporal, causal, degree and several other semantic roles. These various uses can be distinguished from one another on syntactic and semantic grounds. For instance, one distinction between the locative and temporal uses concerns the behavior of the preposition when its dependent nominal constituent is fronted for the purposes of focus. Thus for the locative use the preposition is stranded when the dependent NP is fronted, whereas in its temporal use the preposition is neither stranded nor piedpiped when its NP is fronted. It is deleted. This difference is evident from a comparison of the following pairs of sentences:

a. Me-kpó-e le asi-me

LOCATIVE

1SG see 3SG at market-containing region of

'I saw him/her in the market.'

b. Asi-me-é me-kpj́-e *(le) market-containing region of-aFOC $1 \mathrm{SG}$ see $3 \mathrm{SG}$ at 'In the market I saw him/her.' 
a. Me-kpó-e le gdi-me TEMPORAL

$1 \mathrm{SG}$ see $3 \mathrm{SG}$ at morning-containing region of

'I saw him/her in the morning.'

b. gdi-me-é me- kpó-e (*le) morning-containing region of-aFOC1SG see-3SG at 'In the morning I saw him/her.'

We shall focus on the locative use, which is perhaps the preposition's most basic use. In its locative use it has been suggested that the preposition is used to render the meanings of 'in, on, at ...' (Hünnemeyer 1990: 91). To this, one may add 'from' and further that in some contexts it has no easy translation into English. These glosses are nothing more than contextual modulations on the basic meaning of the preposition. As we shall see below, these translation equivalents are interpretations of the $l e$ preposition based on knowledge about other elements in the construction and of the context.

The basic meaning of the preposition in its locative use may be paraphrased as follows:

$\mathrm{X}$ be at $\mathrm{Y}$

$\mathrm{Y}$ is a place (in relation to something else)

Just as in the case of the verb, the place feature may be inherent in the dependent NP of the preposition or may be specified by a postposition. The only difference between the meaning of the preposition and that of the verb lies in the fact that the preposition does not have a temporal component as the verb does. This follows from two interrelated facts. Firstly, as a preposition, le does not select for tense categories. Secondly, unlike the verb which has a le/no alternation depending on the time of the event being described, the preposition does not have this alternation.

\section{The "division of labor" in spatial description}

One of the major concerns of this paper is to demonstrate that various elements in an Ewe spatial construction "conspire", so to speak, to provide information about spatial scenes. In this section I want to explore how the labor of spatial description is divided between the various component elements. There are suggestions in the literature concerning how the functions are divided between V[erbal]-adpositions and $\mathrm{N}$ [ominal]-adpositions in languages that have both items. Heine et al. (1991b: 140), for example, suggest the following: "[I]n terms of the framework proposed by Talmy (1985), one may say that $\mathrm{N}$-adpositions provide information on the shape and/or dimensionality of the ground, 
whereas V-adpositions are more likely to describe the relation between figure and ground." In the same vein and specifically for Ewe, Hünnemeyer (1990: 92-93) notes that “... with regard to the most concrete, that is, local functions of coverbs (i.e., prepositions, F.A.) and postpositions we can state-in syntactic and semantic terms-that COVERBS (i.e., prepositions, F.A.) establish the local relations thereby simultaneously specifying categories of topological orientation PLACE, GOAL, SOURCE, PATH-whereas POSTPOSITIONS (PPs) localize the complement noun thereby simultaneously specifying kinds of spatial dimensions: INSIDE/ENCLOSURE, OUTSIDE, TOP, BACK, FRONT" (italics in original).

These are higher level generalizations. Here, an attempt is made to go to lower level and more specific ones and to suggest the principles of interpretation that are employed in understanding Ewe spatial descriptions. It emerges that for some spatial descriptions it is the compositional semantics of the prepositions and postpositions as outlined above that are crucial for their understanding. For others, it is the compositional semantics of the preposition and its nominal object that are relevant. For some others, it is the compositional semantics of the preposition or spatial predicate, the nominal reference object and the postposition plus pragmatic conversational implicatures that are required for understanding the spatial description. And for others, it is the union of the spatial semantic feature of the verb which describes the core event and that of the preposition that is prominent for the interpretation of the spatial scenes.

The following spatial construction types will be considered:

\begin{tabular}{|c|c|c|c|c|}
\hline & Figure & spatial relation & reference object & $\begin{array}{l}\text { search domain } \\
(* \text { Postn/[axial nart]) }\end{array}$ \\
\hline (1) & NP & & NP [toponym] & $\begin{array}{l}\text { (*Postp/[axial part }]) \\
\left({ }^{*} \text { Postn } / \text { axial }\right.\end{array}$ \\
\hline (11) & NP & V/Prep & $\begin{array}{l}\text { [X-locative } \\
\text { derivative]N }\end{array}$ & $\left({ }^{*}\right.$ Postp/[axial part] $)$ \\
\hline (iii) & NP & V/Prep & $\begin{array}{l}\text { N[location where } \\
\text { an activity } \\
\text { regularly takes } \\
\text { place] }\end{array}$ & (Postp) \\
\hline (iv) & NP & V/Prep & $\mathrm{N}$ [activity] & (Postp) \\
\hline (v) & NP & V/Prep & $\begin{array}{l}\mathrm{N} \text { [inherent } \\
\text { locative] }\end{array}$ & (Postp) \\
\hline (vi) & NP & Verb and Prep & NP & \\
\hline
\end{tabular}

These will be mostly identified with respect to the nature of the nominal reference object. 
(i) NP[toponym] constructions

The reference objects in such constructions are names of towns and regions. In this type of spatial construction, postpositions are not used to specify the search domain of the reference objects. As Westermann (1930: 56) puts it "No me is added to the names of towns and countries." This observation is couched in specific terms, but it can be expressed in more general terms. The main generalization for these toponyms, as noted above (section 4), is that they can co-occur with postpositions that designate regions adjacent to reference objects, such as $g b b^{\prime}$ 'vicinity', but not with postpositions that denote axial or intrinsic parts of objects such as $m e$ 'in(side)'. Compare the following sentences:
a. Mie- le
Leiden $\left({ }^{*} m e\right)$.
1PL be-at: PRES Leiden containing regions of 'We are in Leiden.'
b. Du má le Kpando gbó lofo.
town that be-at: PRESKpando vicinity around
'That village is in the neighborhood of Kpando.'

The rationale for this behavior seems to be based on the fact that the toponyms are inherent places construed as bounded regions without axial parts. To refer to specific parts or regions of such places direction terms such as dziehe 'south', anyigbe 'downhill, lowland' etc. are used. These are not postpositions and they are linked to the nouns by the possessive connective fé. The direction terms may co-occur with postpositions.

(30) Atikewofé-á le Kpando fé dziehe. hospital DEF be-at: NPRES Kpando poss south 'The hospital is in the southern part of Kpando.'

To understand constructions involving names of places and regions, the semantics of the spatial predicate is unified with the semantics of its inherently locative object. Thus for the interpretation of the sentence in (29a) above the semantics of $l e$, that is, $\mathrm{X}$ be at $\mathrm{Y}$, unifies with the semantics of the other elements in the expression. In this process $X$ is linked with Mie 'we' and ' $\mathrm{Y}$ is a place' is linked with Leiden. There is no specification of where exactly in Leiden. It is treated as a point or a bounded region.

\section{(ii) $N$ with locative derivative in its composition}

This is another type of spatial construction in which postpositions are not normally used to indicate the search domain. In these constructions 
the reference object is represented by a nominal which is morphologically headed by a derivative postposition. In this, as in the first construction type, non-axial part postpositions can occur. In addition, direction terms may be used to indicate the specific region of the reference object (see example [31c] below). Compare the sentences in (31) which can be used to describe the same real world spatial scene.
a. Núdudu-a le
$d z o-d o ́-f e ́-\quad a ́$
food DEF be-at: PRES fire-set-place DEF
$\left({ }^{*} m e\right)$
containing region of
'The food is in the kitchen.'
b. Núdudu-a le xo- a $\left({ }^{*} m e\right)$
food DEF be-at: PRES room DEF containing region of 'The food is in the room.'
c. Núduqu-a le dzo-dó-fé á fé dzogoe food DEF be-at: PRES fire-set-place DEF poss corner me
containing region of
'The food is in the corner of the kitchen.'

The noun $x o$ 'room, building' is a noun that designates an entity as a place but it is neither a place name nor is it headed by a derivative postposition in its morphological structure. It therefore requires a postposition for the specification of the search domain.

In the two types of constructions discussed so far, the absence of a postposition in the linguistic expression can be explained by the semantics of the nominal that represents the reference object. It can also be said that the interpretation of the construction is the result of the interaction between the semantics of the spatial predicate and the semantics of the nominal that represents the reference object (leaving aside the cases where the search domain specification is provided by direction terms).

There are other instances where pragmatic and world knowledge enter the process of understanding and interpreting spatial descriptions. Thus there are a number of nouns which are inherently locative in the sense that they designate places where people live or do things regularly. These nouns may take postpositions for different reasons.

\section{(iii) N locative with an associated regular activity}

One group of these nouns consists of elements that refer to a place as well as the activities that take place there. Some of these nouns are suku 
'school' and agble 'farm'. To express the fact that a Figure is located at or involved in the activities associated with these places, no axial part postpositions are normally used. Consider the following:
Fofó- nye le
agble.
father 1SG be-at: PRES farm
'My father is at the farm.'

Contra the suggestion in Westermann (1930: 55-56) that these nouns do not take postpositions, one encounters sentences of the following kind where they do occur with postpositions, especially the me 'containing region of' postposition.

Fofó- nye le agbleme.

father 1SG be-at: PRES farm containing region of

'My father is in the farm.'

The conversational implicature associated with the constructions with a postposition is that the speaker and the addressee understand and know which particular place the Figure is usually located at. Furthermore, there is the specific suggestion that the Figure is located within the bounds of the place. The constructions without the postposition, as in (32) above, on the other hand, are more generally interpreted as the Figure is engaged in an activity associated with the place without necessarily being located there.

\section{(iv) $N$ [activity] with or without postposition constructions}

A second group of nouns are those that denote activities or events such as takpékpé 'meeting', ava 'war' etc. These nouns are not inherently locative but they can occur with or without postpositions in spatial constructions.

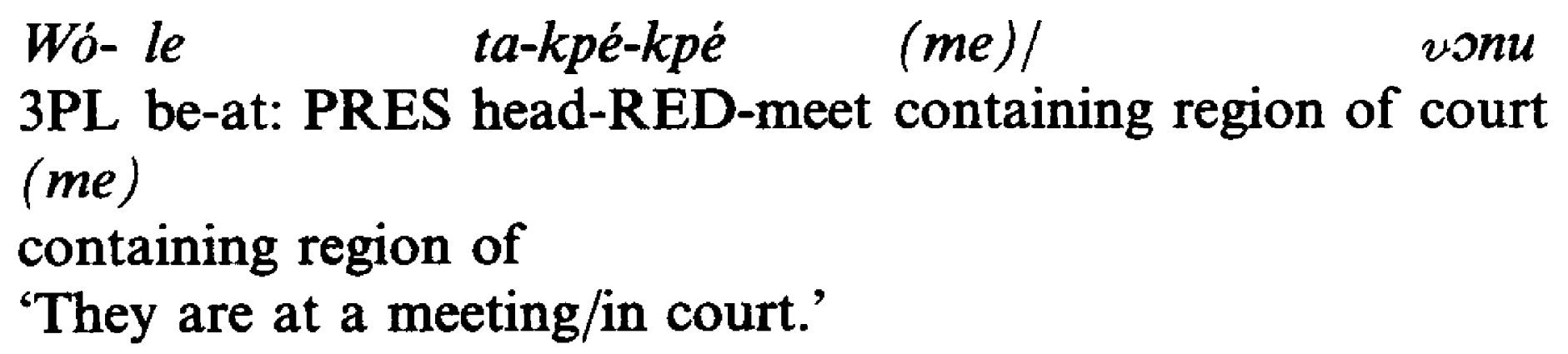

The interpretation of such spatial constructions involves the interaction of the literal semantics of the forms and the application of some pragmatic principles. The first pragmatic principle at work is a metonymic rule based on real world knowledge whereby events that are held in specific places may be understood as places. This metonymic principle allows for the event nominals to be interpreted as locative. Given this locative 
feature, the co-occurrence of the nouns with or without postpositions is then interpreted on the basis of the conversational implicature outlined above for the first group of nouns. That is, for the constructions without a postposition the Figure is understood to be involved in something associated with the event in general. For the constructions with the postpositions, the implicature is that the Figure is engaged in an event at the specific place that is understood and known by the speaker and the addressee. ${ }^{10}$

\section{(v) $N$ [inherent locative] with or without postposition constructions}

The third group of nouns comprises those that are inherently locative such as afé 'house, hometown', anyigbá 'ground, earth, land, country', xéxé 'outside, world, ambience', etc. For these nouns, their occurrence with or without a postposition is used to make sense discriminations of the lexeme. Compare the following sets of sentences:
a. É- dzilá wó le
afé.

3SG parent PL be-at: PRES home

'His/her parents are at home (i.e., native homeland).'

b. É- dzilá wó le afé (-á) me.

3SG parent PL be-at: PRES home DEF containing region of 'His/her parents are at home (i.e., in the house).'

a. deví gede-wó le xéxé. child several-PL be-at: PRES outside

'There are several children outside.'

b. deví gede-wó le xéxé á child several-PL be-at: PRES outside DEF me.

containing region of

'There are several children in the world.'

c. Avuvo le xéxé á me. cold be-at: PRES outside DEF containing region of lit: There is cold in the world 'It is cold.'

The interpretation of the forms without a postposition is fairly straightforward. The interpretation is derived from the compositional semantics of the spatial predicate and the nominal. For instance, the interpretation of (36a) above is that several children are located outside. And the reference of 'outside' is derived from the pragmatic context as 'outside 
of the place where we are or which is the topic of our talk.' To a certain extent, the understanding of the constructions with postposition would seem to follow the same principles as those outlined for inherently locative nominals like agble 'farm' discussed above. That is, the constructions with the postposition are understood and applied as having a more local focus compared to those without postpositions which are understood as being more generally applied. Indeed the optional presence of the definiteness marker in the constructions with postpositions would seem to support this view. The postposition helps to zero in on a specific part of the place designated by the noun. However, there is a difference between the group of nouns being discussed here and those discussed earlier: the readings of the nouns under current discussion are lexicalized while those of the other class are not.

One piece of evidence in support of this claim is that the principles of interpretation that are applicable to the agble 'farm' type constructions do not apply to the constructions involving anyigbá 'ground' for example. Consider the following examples and their interpretations:
a. $A w u-$ a le
anyigbá $\left({ }^{*} d z i\right)$
garment DEF be-at: PRES ground upper surface
'The garment is on the ground/floor.'
b. Ame geqe-wó le
anyígbá *(dzi)
person several-PL be-at: PRES ground upper surface
'There are several people on earth.'

One would have expected the postpositional construction to have a local interpretation, that is, to be used to describe location on the ground or floor, but the reverse is the case. It is the postpositional construction that is more generally applied in a sense. It is this quasi tautology which seems to trigger a specific pragmatic inference which is pragmaticized as an interpretation of the nominal. Thus for the constructions with only the inherently locative nouns, the compositional semantics of the spatial predicate and the noun yield a straightforward locative interpretation which, depending on the context, is sufficient for locating the Figure. For those constructions with the postpositions, a pragmatic inference is triggered which signals that a specific reading of the nominal should be invoked. For example, the presence of a postposition with the nominal anyígbá 'ground' signals that this noun should be read as land, country or earth depending on the specific discourse and contextual factor.

\section{(vi) Verb and preposition unification constructions}

Up to this point, we have been discussing the interaction between the meanings of the nominal designating the reference object and of the 
presence or absence of postpositions that specify the search domain. Another dimension of the understanding of spatial descriptions relates to those constructions in which the spatial feature of a verb that codes the core situation in which the Figure is involved and the semantics of the spatial predicate, i.e., the preposition which signals the relation between the Figure and the Ground. Consider the following sentences:

Agálã do le do me.

crab exit at hole containing region of

lit: The crab exited at the containing region of the hole 'The crab has got out from the hole.'

\section{Ma- dzó le afí-sia égbe.}

1SG: FUT leave at place-this today

lit: I will leave at this place today

'I will leave (from) this place today.'

In the sentences above, the preposition le 'at' may be rendered in English as 'from'. But this is not just a rendition of the preposition, it is the result of the interaction between the source feature encoded in the verb plus the 'at' meaning of the preposition. The verb do could be paraphrased as 'move out of a place thought of as an enclosed/bounded region/place'. In example (38) above the place where the crab moves out of is do 'hole'. This place is construed as an enclosure, that is, the inside of a hole as signalled by the postposition me 'containing region of'. This meaning unifies with the meaning of 'be at a place' of the preposition to produce the literal meaning of the utterance.

On another level, the semantics of the verb that describes the core event characterized in the clause interacts with and determines the choice of the preposition used to describe the location of the Figure. Ewe maintains a systematic distinction between static and dynamic location which is coded by the choice of prepositions. The preposition le always expresses static location, whereas the choice of other prepositions like dé 'to(wards)' and tsó 'from' for the expression of location indicates that the location is viewed as a dynamic one. For example, the sentences in (41) can be given as answers to the topic-only question in (40) asking about the location of the garment.

(40) Awu- a dé? garment DEF $Q$

'Where is the garment?' 
(41) a. Me-kpó awu lá le/*á ka- a dzí.

1SG see garment DEF at to rope DEF upper surface

lit: I saw the garment at the upper surface of the line

'I saw the garment on the line.'

b. Me-sía awu lá dé/*le ka- a dzí.

$1 \mathrm{SG}$ dry garment DEF to at rope DEF upper surface

lit: I put out to dry the garment (move) to the upper surface of the line

'I dried the garment on the line.'

Significantly, dé is unacceptable in the first sentence which describes a static situation-the fact that I saw the garment on the line. Similarly, le is unacceptable for describing a situation which involves an activity of exposing the garment to dry in the second sentence.

The same contrast between static and dynamic location can be observed when the sentences in (42) below are compared.

\section{a. '́- fle avo le Áma gbó.}

3SG buy cloth at Ama vicinity

lit: S/he bought cloth at the neighborhood of Ama

'S/he bought a piece of cloth from Ama.'

b. É- fle avo tsó Áma gbó.

3SG buy cloth from Ama vicinity

lit: $\mathrm{S} /$ he bought cloth from the neighborhood of Ama

'S/he bought a piece of cloth from Ama.'

The two sentences in (41) can describe the same scene and they are both indeed translated idiomatically in the same way in English. Nevertheless, the Ewe forms differ with respect to the preposition that is used to signal the relation between the Figure avo and the reference object and its search domain. The claim being made is that the sentence with the preposition $l e$ is presented as a static relation, the Figure is located at the same place as the reference object. The sentence with the $t$ só preposition on the other hand signals that the Figure moves away from the location of the reference object. It reinforces the transfer nature of the verb, hence the dynamic nature of the location of the Figure.

To sum up, one of the observations that can be made based on the discussion of the constructions in this section is that there appears to be at least two linguistic entities bearing spatial meaning in each construction type. It is also clear that such elements-prepositions, postpositions, spatial verbs etc.- have their own meaning on the basis of which they are deployed in spatial description. Finally, it can be noted that the 
interaction of the meanings yields composite readings which may or may not need pragmatic contextual information to generate an overall interpretation of spatial descriptions. In the next section the behavior of the Ewe forms and their constructions are placed in a cross-linguistic perspective.

\section{Aspects of Ewe spatial constructions in cross-linguistic perspective}

Thus far, the linear order of elements in an Ewe spatial construction map onto the conceptual categories of spatal description in the following way:

$\begin{array}{llll}\text { Figure } & \text { Relation } & \text { Reference object } & \begin{array}{l}\text { Search domain } \\ \text { NP/Clause }\end{array} \\ & \begin{array}{l}\text { Spatial verb/ } \\ \text { Preposition }\end{array} & & \end{array}$

We have seen that these elements interact in different ways to achieve descriptions and interpretations of spatial scenes. For instance, it was noted that sometimes the search domain is not explicitly coded by a postposition if the reference object is represented by an inherently locative nominal. Thus postpositions do not co-occur with place names. This behavior can be compared to the situation in languages with case systems where nouns referring to places are locally unmarked in the locative and other local cases (Tiersma 1982: 843).

There are other parameters for the comparison of languages with respect to the way in which they resolve the question of the relation between the Figure and the Ground in spatial description. One such parameter concerns the amount of information that is provided about the geometry of the Figure and the Ground, as required by the language, in spatial constructions. Talmy (1983: 233) observes that in spatial description, the geometry ascribed to the Figure is simpler than the geometry of the reference object. This could be formulated as a plausible "natural" universal feature of spatial description, namely "that spatial descriptions specify the geometrical nature of the ground, not the figure" (Levinson 1991: 9).

As Levinson argues, this statement applies to English spatial descriptions but it is not an absolute universal. This is because in Tzeltal (and other Mayan languages) "the ... English strategy of presupposing the structure of the figure, but detailing the nature of the ground ... is not followed. Instead Tzeltal takes the strategy of specifying in great detail the figure, while presuming the general nature of the ground" (Levinson 1991: 10). Thus English and Tzeltal are different.

In the description of spatial configurations, Ewe is like English in not providing too much information about the Figure, but it provides details 
about the relevant spatial schemas of the reference object through the use of postpositions. Thus Ewe is also unlike the Mayan languages.

However, Ewe is unlike English, to some extent, in terms of the degree to which information about the reference object is provided. Ewe provides more precise information about the nature and the dimension of the reference object (especially if it is not inherently locative) than English does. Thus in English, a sentence like (43) below is vague, I believe, between the sentences in (44a and $44 b)$.

(44) a. He is on top of the car, i.e., on the roof of the car.

b. He is on the bonnet of the car.

This vagueness is coded explicitly in Ewe by different postpositions: for (44b), the postposition tame 'apex' will be used while for (44a) the postposition $d z i$ 'upper surface' will be used. Hence sentence (43) will be rendered in Ewe as either (45a), corresponding to (44a), or (45b), corresponding to (44b), depending on which scene is being described.
a. $\quad \dot{E}-\quad l e$
vu- $a$ ta-me.
3SG be-at: PRES car DEF head-containing region of
[He is at the apex of the car]
'He is on (top of) the car.'

b. $\quad E-l e \quad v u-a \quad d z i ́$.

3SG be-at: PRES car DEF upper surface

[He is at the upper surface of the car]

'He is on (the bonnet of) the car.'

Thus contrary to the suggestion by Heine et al. (1991b: 129) that the postpositions $d z i$ and tame "[b]oth mean 'on, above' and are largely synonymous", I hope the above examples show that they mean different things and that they are used to make subtle semantic distinctions in the description of spatial configurations.

Similarly, the location of a picture with respect to a wall can be described in one of the following ways depending on where on the wall it is.

(46) Fóto lá le gli lá gú. picture DEF be-at: PRES wall DEF side [the picture is on the side (surface) of the wall] 'The picture is on the wall.' 

(47) Fóto lá le gli lá ta-me. picture DEF be-at: PRES wall DEF head-containing region of [the picture is on the apex of the wall] 'The picture is on (the higher part of ) the wall.'
(48) Fóto lá le gli lá dzí. picture DEF be-at: PRES wall DEF upper surface [the picture is on the upper surface of the wall] 'The picture is on (top of) the wall.'

Each of these sentences can be rendered in English as "the picture is on the wall" as the translations show. But Ewe makes use of postpositions to give precise information about the specific location of the picture. For instance, the distinction between (47) and (48) above has to do with the level or height of the wall at which the picture is from an anthropomorphic point of view. If the upper flat surface of the wall where the picture hangs is such that one can see the picture on it, then the dzi postposition is used as in (48). However, if the picture is not accessible to the direct perception of people (cf. Vandeloise 1991), that is, the picture is at the upper flat surface level of the wall higher than where one can easily see it, then the postposition tame is used as in (47). Ewe thus forces its speakers to provide more information about the specific part or region of the reference object where the Figure is located than English does. English speakers can decide to be as precise about the part of the reference object where the Figure is located as the Ewe speakers do, but they are not obliged to do so by the language. The point is that in Ewe it is obligatory to give precise information about the reference object while in English it is not. Thus the same nuances described above for sentences (46) to (48) can be made in English but they must be made in Ewe.

One can also compare languages in terms of how they frame and package information about the relation between the Figure and the Ground in adpositions. These Ewe data and similar data from other languages with two sets of adpositions, such as Hausa and Maa, show that these languages employ a strategy that is distinct from the strategy employed by European languages, such as English, which have only one set. We have already noted the highly perceptive observation by Heine et al. (1991b: 144) that prepositions in European languages combine the functions of both $\mathrm{V}$ - and $\mathrm{N}$-adpositions. ${ }^{11}$ The claims made in this paper support this view.

One of the implications of this view is that a preposition like on which has been assumed to be cognitively basic in some studies (e.g., Herskovits 1986) are rather complex. The preposition on is perhaps made up of a 
relation of 'be somewhere' which is basic and universal (Wierzbicka 1992 ) and the relations of support and contact which are not necessarily basic. ${ }^{12}$

The linguistic systems of spatial description can also be compared in terms of what they require to be stated about spatial configurations and what can be left to pragmatics. Using this parameter, Ewe and similar languages and the European languages look less dissimilar. In Mparntwe Arrernte (Australian) the linguistic representation in (49) can be appropriately interpreted in context in one of the ways represented in (50) (David Wilkins p.c.).

(49) Tyampite ure-le ne-me.

billy can fire-loc sit/be-PRES

(50) The billy can is on/besides/in/above the fire.

However, spatial nominals and adverbials may be used to specify the relevant search domain with respect to the reference object as indicated in $(51)$.

Tyampite ure itere-le/ kwene-le/ kertne-le ne-me.
billy can fire side-loc/inside-loc/on/over-loc sit/be-PRES

Note that there is no equivalent of the Arrernte sentence in (49) in Ewe. To express the ideas represented in (50) in Ewe, the verb le 'be-at' and the appropriate postposition will have to be used. Furthermore, since $d z o$ 'fire' is not treated as an inherently locative construction a postposition is obligatorily required (see [52] below). Similarly, a preposition is required in English.

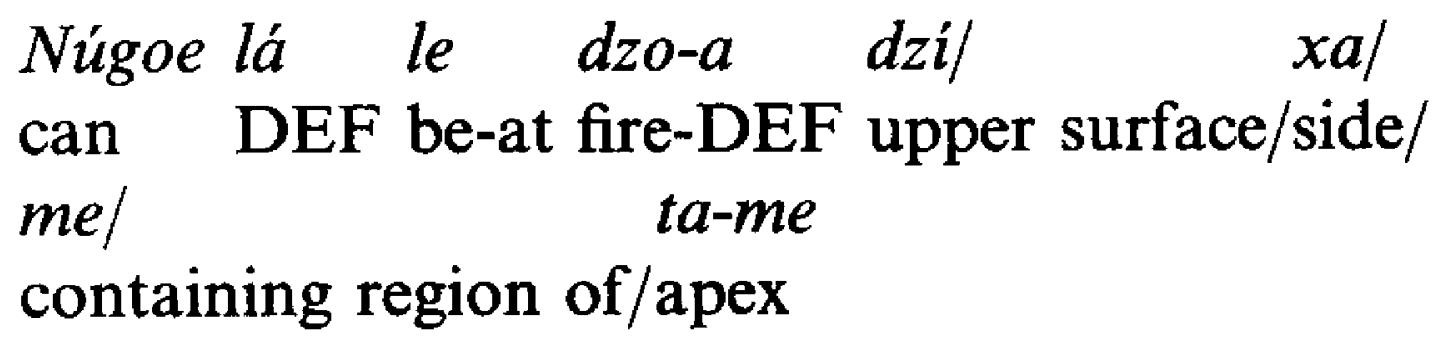

In Arrernte however, given sufficient context, the locative case marker is all that is needed for describing any of the spatial configurations represented with the English prepositions. The Arrernte utterance is left to be interpreted through the pragmatics of the situation. From the point of view of this aspect of Arrernte, European languages, including English, and Ewe and languages like it look similar in terms of the specification of location in linguistic forms. But in the absence of an appropriate context and where the spatial relation is deemed to be of particular relevance, Arrernte becomes like Ewe with a spatial nominal/adverbial determining spatial parts/regions and case establishing the various sorts 
Table 3. A comparison of three languages

\begin{tabular}{|c|c|c|}
\hline Language & $\begin{array}{l}\text { Relational and Ground } \\
\text { information }\end{array}$ & $\begin{array}{l}\text { Obligatoriness of coding } \\
\text { information }\end{array}$ \\
\hline Ewe & $\begin{array}{l}\text { Relational information: } \\
\text { prepositions, spatial verbs; } \\
\text { Ground information: } \\
\text { postpositions }\end{array}$ & $\begin{array}{l}\text { Both types of information } \\
\text { obligatory except when the } \\
\text { reference object is a toponym, a } \\
\text { locative nominal associated with a } \\
\text { customary activity, an activity } \\
\text { nominal understood as } \\
\text { representing a place, a nominal } \\
\text { which contains a postposition in } \\
\text { its composition }\end{array}$ \\
\hline English & $\begin{array}{l}\text { Portmanteau markers: } \\
\text { prepositions }\end{array}$ & Obligatory \\
\hline Arrernte & $\begin{array}{l}\text { Relational information: } \\
\text { case marker; } \\
\text { Ground information: } \\
\text { spatial nominals/adverbials }\end{array}$ & $\begin{array}{l}\text { Preference not to use search } \\
\text { domain specifier with respect to } \\
\text { the reference object if context is } \\
\text { sufficient }\end{array}$ \\
\hline
\end{tabular}

of possible spatial relations. Languages would seem to have different degrees of how precise and informative they are about the location of things in relation to the reference object and to what extent this information must be explicitly coded. Table 3 illustrates the contrasts between Ewe, Arrernte and English-three genetically and typologically diverse languages-with respect to this feature.

\section{Conclusion}

The paper has provided a description of the grammar, meaning and interpretation of adpositions in Ewe. There are a number of implications of the study for the theory and description of spatial constructions in individual languages and for the investigation and understanding of crosscultural and cross-linguistic spatial conceptualization. At a general theoretical level, the paper has been an exploration in the role of compositionality and its interaction with pragmatics to yield understandings of spatial configurations as represented linguistically in Ewe. There are some hints in the literature with respect to the interpretation of spatial constructions, but these are mostly based on Indo-European languages. Thus Senft (1992: 12) observes that:

To interpret a preposition like 'in' in the sentence "The socks are in the drawer" we must know the meaning of the expression that encodes the spatial information given (in = contained in), we must combine this meaning with additional information given in the context (e.g., with the verb 'are'), and it must be clear 
that the speaker of this sentence has more or less the same concept of space, of the 'referential domain', as the hearer. It is only with these three components of spatial reference, namely, meaning, context and space conception, that we can infer the function and the interpretation of an expression like "in" (see also Herskovits 1986: 3).

While this is true for all languages including Ewe, such examples tend to mislead one into thinking that spatial relational information is coded in a single form. Clearly, the examples from Ewe show that such meanings may reside in more than one form and one needs a level of integration and unification for the interpretation of spatial expressions. These meanings cannot be simply read off one form (see also Sinha and Kuteva 1994).

On another level, the discussion of the different construction types in section 7 confirms Miller and Johnson-Lard's (1976: 380) comment with respect to the semantic analysis of spatial expressions. They wrote: "Semantic analysis of spatial locatives is complicated by strong interdependencies between the preposition and the relatum ... it is not possible to analyze spatial locatives without taking into account the kind of landmarks which can serve as their relata." It has been shown in this paper that this observation holds for the two classes of adpositions in languages that have them. We saw how in Ewe it was necessary to specify the feature of the complement of the spatial predicate le 'be at' and how different interpretations may be produced depending on the way in which the reference object is construed with respect to the postpositions.

At a language specific level, the paper has shown the relevance of the distinction between axial or intrinsic parts and regions as reflected in the grammar of postpositions in Ewe. This has greatly enhanced our understanding of the enigmatic behavior of postpositions in possessive constructions in the language. In addition the paper has underscored the importance of a distinction that has seldom been recognized in the spatial conceptualization literature between the notion of "place as an entity" and "place as a relation". The general manifestation of this is the opposition between postpositions and prepositions in Ewe, but several other languages manifest this in different ways. ${ }^{13}$

Finally a comparison of the Ewe system to other languages has drawn attention to a possible typology of languages in terms of where relational and ground information is coded and how obligatory it is for this kind of information to be coded in a spatial description. It is hoped that this paper has highlighted the relevant dimensions needed in the investigation of spatial language and conceptualization in a non-Indo-European language of the type which has two sets of adpositions. 


\section{Notes}

1. The subject matter of this paper was first presented at the "Workshop on Spatial Language and Cognition" in Sandbjerg, Denmark, in June 1993. I am very grateful to Chris Sinha for inviting me to the workshop and for his editorial guidance, interest and, above all, patience. Words cannot adequately express my indebtedness to Debbie Hill and David Wilkins for their insight, advice and encouragement at every stage of the development of the paper. I would also like to thank Caroline Angenent, Anneke Breedveld, Bob Bugenhagen, Chris Collins, Gerrit Dimmendaal, James Essegbey, Cliff Goddard, Sabine Neumann and Mathias Schladt for their comments and suggestions on earlier versions of the paper.

2. Ewe orthography and abbreviations: In the traditional orthography of Ewe, only few tones are marked. In this paper, all high tones are marked throughout with an acute accent '. Low tones, marked with a grave accent ', are only indicated when demanded by the orthography or to make explicit the tone of the item being discussed. Rising and falling tones are marked by ă and â respectively where necessary. $f$ and $v$ are the orthographic forms for $/ \phi /$ and $/ \beta /$ respectively. The following abbreviations are used in the interlinear glosses:

$\begin{array}{llll}\text { ALL } & \text { allative preposition } & \text { PFV } & \text { perfective } \\ \text { COMP } & \text { complementizer } & \text { PL } & \text { plural marker } \\ \text { DEF } & \text { definite article } & \text { poss } & \text { possessive linker } \\ \text { EMPHQ } & \text { Emphatic question marker } & \text { Postp } & \text { postposition } \\ \text { aFOC } & \text { argument focus marker } & \text { Prep } & \text { preposition } \\ \text { FUT } & \text { future } & \text { PRES } & \text { present } \\ \text { gen } & \text { genitive } & \text { PRO } & \text { invariable pronominal } \\ \text { HAB } & \text { habitual } & \text { PROG } & \text { progressive } \\ \text { INGR } & \text { ingressive } & \text { Q } & \text { question marker } \\ \text { INDEF } & \text { indefinite } & \text { RED } & \text { reduplicative formative } \\ \text { loc } & \text { locative case marker } & \text { SG } & \text { singular } \\ \text { LOG } & \text { logophoric pronoun } & \text { TP } & \text { terminal particle } \\ \text { NP } & \text { nominal phrase } & \text { VS } & \text { verb satellite } \\ \text { NEG } & \text { negative } & 1 & \text { first person } \\ \text { NPRES } & \text { non-present } & 2 & \text { second person } \\ & & 3 & \text { third person }\end{array}$

3. There are slightly different conceptions of the terms for the components in a spatial description. I will outline two of them and present the way in which I use the terms in this paper. Talmy (1983: 232) defines the Ground as "a reference object (itself having a stationary setting within a reference frame) with respect to which the Figure's site, path, or orientation receives characterization." Talmy uses Ground and reference object interchangeably. Levinson (1991: $8 \mathrm{fn} \mathrm{12)} \mathrm{offers} \mathrm{a} \mathrm{revision} \mathrm{of} \mathrm{Talmy's} \mathrm{notions}$ and argues that Ground is a complex of a relatum-the landmark object, i.e., reference object, the search domain-the space anchored to the relatum in which the referent (i.e., the Figure) is to be found-and the relation between the referent and the landmark as specified by the spatial predicate and/or adposition. Levinson adds that the relation "normally serves to specify and delimit the search domain projected off the relatum" (Levinson 1992: $11 \mathrm{fn} 24$ ). I take the view that the Ground is a complex of (i) the reference object (relatum in Levinson's terms) and (ii) the search domain as specified by an adposition. But the Ground for me excludes the relation. This is the 
difference between my view and that of Levinson as is evident from a comparison of

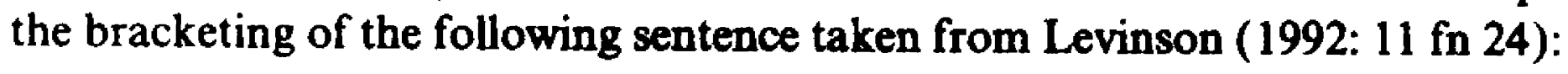

\begin{tabular}{|c|c|c|c|}
\hline referent & $\begin{array}{l}\text { Ground } \\
\text { relation }\end{array}$ & relatum & \\
\hline [The cat] & [[is near] & [the couch]] & \\
\hline Figure & relation & $\begin{array}{l}\text { Ground } \\
\text { search domain }\end{array}$ & reference object \\
\hline
\end{tabular}

(Levinson)

[the couch]]

(Ameka)

4. In a sense, it may be more accurate to say that the reference object is also part of the search domain. If one adopts this view, then the postposition is strictly speaking a search domain functor. I will continue to use the search domain in the restricted sense of search domain functor throughout the paper.

5. 'The locative prepositions (in, on, at) correspond in Ewe at one and the same time to a verb and a locative noun: on the way: le mo dzi; on: le ... dzi.'

6. To avoid confusion, perhaps one should add a clarification here about the term postposition. In one use of the term, postposition is only a positional variant of preposition. Thus SOV languages tend to have postpositions while SVO languages have prepositions. In some other languages the same locative particle can function either as a preposition or a postposition creating different contextual senses of the particle. Compare these Dutch sentences:

\section{Hij loopt op de dak. 'He walks on the roof.' (Preposition) \\ Hij loopt de dak op. 'He walks up the roof.' (Postposition)}

The similarity between these uses of the terms and the way it is used with respect to Ewe is with respect to the position of the locative grammatical item that occurs postposed to its nominal complement. Its functions do not entirely cover those of prepositions (which could occur as postpositions in other languages) as we shall see in the rest of the paper.

7. Langacker (1993: 335) notes that the following sentences in which prepositional phrases function as subjects are marginal for some speakers of English: '?Near the fire is warmer.' and '?Under the bed is all dusty.' The translation equivalents of these sentences in Ewe are perfectly acceptable. The explanation that Langacker offers for their use in English supports the claim being made here with respect to postpositions in Ewe, namely that "the prepositional phrase is construed as naming a spatial region, not a locative relationship. ... [they] are ... best analyzed as designating regions in space ..." (1993: 335, italics in original)

8. In Ewe, [d], [1] and [r] are allophones and the liquids (and glides) are the only consonants that can occur as second consonants in a cluster. In this environment, [1] occurs after grave sounds. Thus the form * $k p q e ́$ becomes $k p l e ́$.

9. Other writers have provided variations on the same theme. I will cite only two here: G. Lakoff (1987: 518) comments as follows: "things that exist, exist in locations" and adds the slogan: "to be is to be located." In another vein Lyons (1977: 723) claims that "existence is but the limiting case of location in an abstract deictically neutral space."

10. Chris Sinha pointed out during the oral presentation of this material that parallel forms and interpretations exist in English as well. Compare the following:

He is at/in the office.

He is at/in a meeting. 
The sentences with at are generally applied to signal the location of the Figure whereas the forms with in signal that the Figure is exactly at that location.

11. But one should note some differences between Ewe on the one hand and Hausa and Maa on the other. First, as we have noted, in Huasa and Maa the V-and N-adpositions are both prepositions whereas in Ewe the $\mathrm{V}$-adpositions are prepositions and the $\mathrm{N}$-adpositions are postpositions. Second, in Hausa and Maa it is the V-adpositions that are optional while in Ewe, as we have seen, it is the $\mathrm{N}$-adpositions that can be left out in a spatial construction. Consider the following sets of sentences from Hausa and Maa:
(1) a. (à) cikin litãfi $\quad$ (Hausa)
at stomach-gen book
'in the book'
b. (à) kân kujẽrã
at head-gen chair
'on the chair' (cf. Cowan and Schuh 1976: 58)

$$
\begin{aligned}
& \text { Eshomo (te) dukuya. (Maa) } \\
& \text { at in front of (<head) } \\
& \text { 'They have gone in front/before.' (Tucker and Mpayei 1955: 43) }
\end{aligned}
$$

Comparing the Ewe, Hausa and Maa data, one is tempted to speculate that there might be a correlation between the position of the $\mathrm{V}$ - and $\mathrm{N}$-adpositions and which of the two would be likely to be optional viz: if the $\mathrm{V}$ - and $\mathrm{N}$-adpositions are both prepositions then the $\mathrm{V}$-adpositions is more likely to be optional than the $\mathrm{N}$-adposition. On the other hand if the $\mathrm{V}$-adpositions are prepositions and the $\mathrm{N}$-adpositions are postpositions then the $\mathrm{N}$-adpositions tend to be optional. However, there is an urgent need for the further investigation especally of the behavior of the adpositions in other languages to verify the validity of such a claim.

12. Compare Lakoff's (1987: 313) comment that "[I]n English the basic spatial use of on makes use of three image schemas-CONTACT, SUPPORT and ABOVE-which form a single conceptual unit."

13. David Wilkins has noted this distinction for Mparntwee Arrernte in an unpublished paper in 1986. Hill (1994) has drawn attention to the presence of this opposition in Oceanic languages. This distinction is also reflected in the use of locative prefixes and suffixes in Bantu languages (Sabine Neumann p.c.)

\section{References}

Ameka, Felix K.

1991 Ewe: Its grammatical constructions and illocutionary devices. $\mathrm{PhD}$ thesis. Australian National University, Canberra.

Ameka, Felix K.

in press Body parts in Ewe grammar. In Chappell, Hilary and William McGregor (eds.), The Grammar of Inalienability. Berlin: Mouton.

Ansre, Gilbert

1966 The verbid: a caveat to serial verbal constructions. Journal of West African Languages 3(1), 29-32.

Boadi, Lawrence A.

1992 Locating objects and events in space. Paper read at the Linguistics Association of Ghana Annual Conference, April 1992. Legon: University of Ghana. 
Bolinger, Dwight

1977 Meaning and Form. London: Longman.

Bowden, John

1992 Behind the Preposition: Grammaticalization of Locatives in Oceanic

Languages. Pacific Linguistic Series B-107. Canberra: Department of

Linguistics, Research School of Pacific Studies, Australian National

Clark, Eve V.

University.

1978 Locationals: existential, locative and possessive constructions. In Greenberg,

Joseph (ed.), Universals of Human Language. Stanford: Stanford University

Press. Vol. 4 [Syntax], 85-126.

Claudi, Ulrike and Bernd Heine

1986 On the metaphorical base of grammar. Studies in Language 10, 297-335.

Clements, George N.

1972 The verbal syntax of Ewe. PhD thesis. University of London.

Collins, Chris

1993 Topics in Ewe syntax. PhD dissertation. Massachusetts Institute of Technology.

Cowan, J. Ronayne and Russel G. Schuh

1976 Spoken Hausa. Ithaca: Spoken Language Services.

Duthie, Alan S.

in press Introducing Ewe Linguistic Patterns. Accra: Ghana Universities Press.

Heine, Bernd

1989 Adpositions in African languages. Linguistique africaine 2, 77-127.

Heine, Bernd

1992 Grammaticalization chains. Studies in Language 16, 335-368.

Heine, Bernd and Mechthild Reh

1984 Grammaticalization and Reanalysis in African Languages. Hamburg: Helmut

Buske.

Heine, Bernd, Ulrike Claudi and Friederike Hünnemeyer

1991a From cognition to grammar-evidence from African languages. In

Traugott, Elizabeth Closs and Bernd Heine (eds.), Approaches to

Grammaticalization. Amsterdam: John Benjamins, 149-187.

Heine, Bernd, Ulrike Claudi and Friederike Hünnemeyer

1991b Grammaticalization: A Conceptual Framework. Chicago: The University of

Chicago Press.

Herskovits, Annette

1986 Language and Spatial Cognition: An Interdisciplinary Study of the

Prepositions in English. Cambridge: Cambridge University Press.

Hill, Deborah

1992 Longgu Grammar. PhD thesis. Australian National University, Canberra.

Hill, Deborah

1994 Distinguishing the notion PLACE in Oceanic languages. Paper read at

LAUD Symposium on Language and Space, March 1994. Duisburg University.

Hünnemeyer, Friederike

1990 Beyond serial verbs or on the expression of causal meanings in Ewe.

Afrikanistische Arbeitspapiere 24, 91-103.

Kölver, Ulrike

1984 Local Prepositions and Serial Verb Constructions in Thai. Arbeiten des 
Kölner Universalien Projekts 56. Cologne: Institut für Sprachwissenschaft.

Lakoff, George

1987 Women, Fire and Dangerous Things. Chicago: The University of Chicago Press.

Landau, Barbara and Ray Jackendoff

1993 "What" and "where" in spatial language and spatial cognition. Behavioural and Brain Sciences 16, 217-265.

Langacker, Ronald W.

1993 Grammatical traces of some "invisible" semantic constructs. Language Sciences 15, 323-355.

Lehrer, Adrienne

1990 Polysemy, conventionality, and the structure of the lexicon. Cognitive Linguistics 1, 207-246.

Levinson, Stephen C.

1991 Relativity in Spatial Conception and Description. Working Paper No 1. Nijmegen: Cognitive Anthropology Research Group, Max Planck Institute for Psycholinguistics.

Levinson, Stephen C.

1992 Primer for the field investigation of spatial description and conception. Pragmatics 2, 5-47.

Lewis, Marshall

1989 Aspect marking in Gẽgbe prepositions: A Cognitive approach to multicategoriality. Proceedings of the Chicago Linguistic Society 25, 272-287.

Lichtenberk, Frantisek

1991a On the gradualness of grammaticalization. In Traugott, Elizabeth Closs and Bernd Heine (eds.), Approaches to Grammaticalization. Amsterdam: John Benjamins, 37-80.

Lichtenberk, Frantisek

1991b Semantic change and heterosemy in grammaticalization. Language 67, 475-509.

Lord, Carol

1993 Historical Change in Serial Verb Constructions. Typological Studies in Language 26. Amsterdam: John Benjamins.

Lyons, John

1977 Semantics Volume 2. Cambridge: Cambridge University Press.

Miller, George and Philip Johnson-Laird

1976 Language and perception. Cambridge, MA: Harvard University Press.

Rongier, Jacques and Ewonuku K. Tsevi

1988 Apprenons l'Ewe: Miasrõ Evegbe (Volume 1). Paris: L'Harmattan.

Senft, Gunter

1992 Everything we always thought we knew about space-but did not bother to question. Working Paper No 10. Nijmegen: Cognitive Anthropology Research Group, Max Planck Institute for Psycholinguistics.

Sinha, Chris and Tania Kuteva

1994 Distributed spatial semantics. Paper presented at LAUD International Symposium on language and space. Duisburg, March.

Sinha, Chris, Lis A. Thorseng, Mariko Hayashi and Kim Plunkett

1994 Comparative spatial semantics and language acquisition: Evidence from Danish, English and Japanese. Journal of Semantics 11, 253-287. 
Stolz, Thomas and Christa Kilian-Hatz

1992 Comitative, concomitance, and beyond: On the interdependency of grammaticalization and conceptualization. A paper presented at the Linguistics

Talmy, Leonard Society of Belgium special conference, Antwerp, December.

1983 How language structures space. In Pick, Herbert and Linda Acredolo (eds.), Spatial Orientation: Theory, Research and Application. New York: Plenum Press, 225-282.

Talmy, Leonard

1985 Lexicalisation patterns. In Shopen, T. (ed.), Language Typology and Syntactic Description Vol. 3. Cambridge: Cambridge University Press, 57-149.

Tiersma, Peter M.

1982 Local and general markedness. Language 58, 832-849.

Tucker, A. N. and J. Tompo Ole Mpayei

1955 A Maasai grammar (with vocabulary). [Publications of the African Institute,

Vandeloise, Claude

Leyden 11]. London: Longmans, Green and Co.

1991 Spatial Prepositions: A Case Study from French. Chicago: The University of Chicago Press.

Westermann, Diedrich

1905 Wörterbuch der Ewe-Sprache. Teil 1. Ewe-Deutsches Wörterbuch. Berlin:

Dietrich Reimer.

Westermann, Diedrich

$1930 \quad$ A study of the Ewe language. Oxford: Oxford University Press.

Wierzbicka, Anna

1992 Lexical universals and universals of grammar. In Kefer, Michel and Johan van der Auwera (eds.), Meaning and Grammar: Cross-linguistic Perspectives. Wilkins, David P.

Berlin: Mouton de Gruyter, 383-415,

1986 Particles/clitics for criticism and complaint in Mparntwe Arrernte (Aranda).

Journal of Pragmatics, 10, 575-596.

Wilkins, David

1989 Mparntwe Arrernte: Studies in the structure and semantics of grammar.

Wilkins, David P.

$\mathrm{PhD}$ thesis. Australian National University.

1992 Interjections as deictics. Journal of Pragmatics 16, 119-158.

Wilkins, David P. and Deborah Hill

1995 When "go" means "come": Questioning the basicness of basic motion verbs. Cognitive Linguistics, this issue.

\section{Ewe Texts}

Akpatsi, Robert S. 1980. Ame adeke menya etso me o [Nobody knows tomorrow]. Accra: Bureau of Ghana Languages.

Akotey, Klu. 1988. Ku di fo na wo [Death satisfied them]. Accra: Bureau of Ghana

Languages.

Nyaseto [a monthly newspaper] Ho: Volta Trust.

Nunyamo 2B Accra: Bureau of Ghana Languages. 
